\title{
Fault Tree Analysis in the Reliability of Heavy Fuel Oil Supply
}

\author{
Ivana Golub Medvešek, Joško Šoda, Tina Perić
}

Marine systems are complex and through the analysis of their reliability it is necessary to observe the reliability of their subsystems and components. With regard to the fact that the reliability is functionally dependent on faults, for the purpose of this study special attention has been given to possible faults on the heavy fuel oil supply pump of a two-stroke marine diesel engine MAN B\&W 5L90MC. A deductive approach to reliability analysis, i.e. fault tree analysis method (FTA), has been used. By the use of this method it is simpler to identify the system's weak link and it is shown that the method gives the basis for the ship's system reliability analysis. Based on FTA analysis this paper suggests system parameters that require continuous monitoring in order to achieve reliability. The results show the behavior of the components in case of faults and this approach can help to create a plan of action in order to enforce timely corrective and preventive action and, accordingly, increase the rate of reliability of the entire ship's systems.

\section{KEY WORDS}

\section{$\sim$ Reliability}

$\sim$ Marine systems

$\sim$ Supply pump

$\sim$ Fault tree analysis

\section{INTRODUCTION}

Marine ship systems are very complex. They consist of a large number of subsystems and components whose functionality and quality interaction are of essential importance for high efficiency, long operational lifetime and safety. Therefore, the basic requirement that marine systems have to fulfil is reliability. The concept of reliability of marine systems means the probability that the system will successfully perform its function in terms of the environmental conditions and in specific period of time.

Reliability is functionally dependent on the failures that can occur in any component of marine systems. The aim of this study is to show the dynamics of reliability depending on the fault and the methods and procedures which actively participate in the identification of weak points of marine systems.

In this paper, a deductive approach to analyzing the failure, fault tree analysis method, is used. Special attention is devoted to the most common failures that can happen to a heavy-fuel-oil supply pump, which has significant consequences for the entire heavy fuel oil marine engine system.

The paper is organized as follows: the first paragraph is the introduction. The second paragraph describes reliability based on faults and gives mathematical backgrounds of the proposed paper. The third paragraph is the study of the fault tree analysis in the reliability of marine heavy-fuel-oil supply pump based on the MAN B\&W 5L90MC marine engine. The fourth paragraph is the conclusion, where basic conclusions are given. 


\section{RELIABILITY BASED ON FAULTS}

In the following paragraph basic definitions and mathematical backgrounds on reliability based on faults will be given. Operating reliability is a basic requirement that is put in front of marine systems and it is commonly violated by appearance of faults. Figure 1 shows the graph of fault rate as a measure of reliability. It is well known that reliability is the probability that the system will adequately fulfil its purpose. In the context of reliability, the concept of satisfactory performance is directly linked with the concept of fault or delay (Lovrić, 1989).

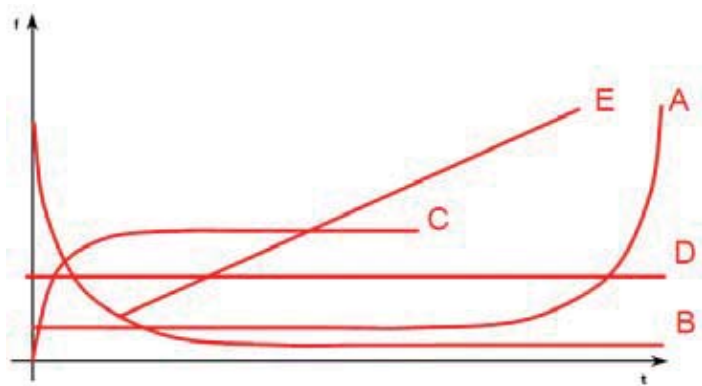

Figure 1.

Faults rate graph as a measure of reliability.

where (Barle, 2001):

$\mathrm{t}$ - time of use;

$f-$ frequencies of faults;

A - a uniformed frequency of fault rate with a slight increase ending in the rapid increase i.e. wear period - typical for engines;

B - initial or early faults, after which the frequency decreases rapidly - typical for on-board electronics;

C - low faults frequency followed by its relatively rapid increase in steady state level which is often the behaviour of the system after processing cycles;

D - relatively constant value of probability of faults, unprofessional uses or unanticipated effects of the environment;

E - continuous increase in the faults frequency with no apparent wear period that is typical for turbines.

According to (Mrčelić, 2010) faults can be classified as:

1) non-inherent faults, i.e. faults characteristic for normal operation;

2) inherent faults, i.e. faults characteristic for the system
a) early,
b) chance,
c) wear-out faults.

The initial use of a system usually implies a higher number of faults that are attributed to errors in production and are called early faults. It is necessary to point out that with early faults fault frequency rapidly decreases over time. On the contrary, there are also chance faults that are of unknown cause, cannot be prevented, but the delays they cause can be prevented. Faults as results of wear and aging appear due to the process of wear and their characteristic is that their intensity grows with time. The combined reliability includes chance faults and faults due to wear.

\subsection{Reliability based on chance faults}

The ratio of the components in faulty and correct components represents the index of chance faults (Lovrić, 1989) that can be described as:

$\lambda=\frac{1}{P_{s}} \cdot \frac{d p_{f}}{d t}$

where: $\lambda$ - an index of faults, $P_{s}$-the number of components that remain correct at the end of this period, $P_{f}$ - the number of components that have failed, $t$ - time.

Equation of reliability for devices with the index of chance faults can be expressed by (2) and is valid only for the period of the initial fault for the period of wear (Mrčelić, 2010):

$R(t)=e^{-\lambda \cdot t}$

Mean Time Between Failures (MTBF) is marked by the index $m$, and can be calculated according to (3):

$m=\int_{0}^{\infty} R(t) \cdot d t=\int_{0}^{\infty} e^{-\lambda \cdot t} \cdot d t=\frac{1}{\lambda}$

The reliability of chance faults can be derived by using expression (3):

$R(t)=e^{-t / m}$

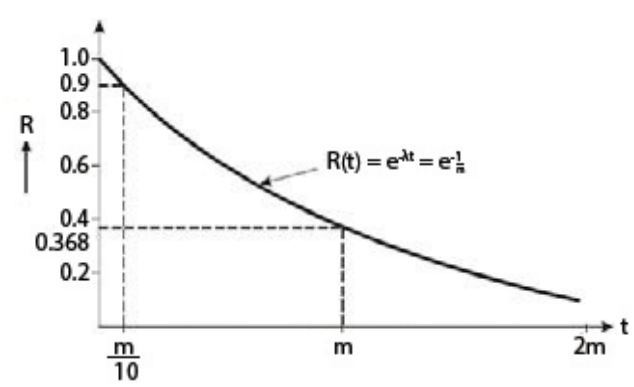

Figure 2.

Standardized curve of reliability. 
Figure 2 shows the standardized curve of reliability that provides basic information about the degree of the remaining reliability as function of mean time, or a part of mean time between faults.

The characteristic parameter $\mathrm{m}$ is the point on ordinate axis where tangent from the maximum slope point crosses the ordinate.

\subsection{Reliability based on wear-out faults}

Without timely replacements of the worn parts, system reliability based on wear follows a normal (Gaussian) distribution according to expression (5):

$R_{W}(T)=\frac{1}{\sigma \cdot \sqrt{ } 2 \pi} \cdot \int_{T}^{\infty} e^{\frac{(T-M)^{2}}{2 \cdot \sigma^{2}}} \cdot d t$

where: $R_{w}(T)$ - reliability based on wear, $\sigma$ - standard deviation, $T$ - total accumulated time of system operation, $M$ - average life time.

Also, the index of faults caused by wear is expressed in the number of faults per hour and shown in equation (6):

$\lambda_{m}=\frac{r}{\sigma}$

where: $r$ - index of wear-out faults.

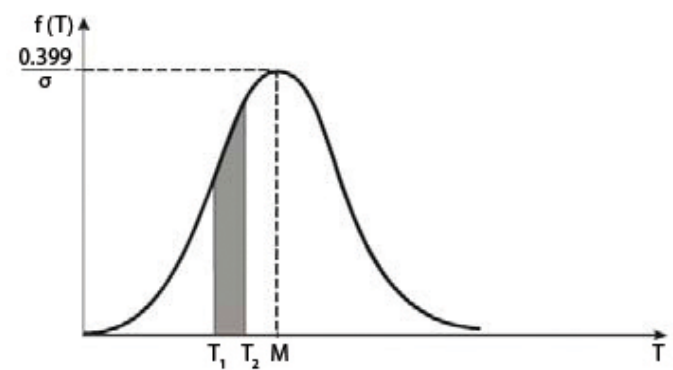

Figure 3.

Normal distribution because of wear-out faults.

Figure 3 shows a normal distribution of wear-out faults. The highest density of a system's faults occurs in an average lifetime $M$. The area under the density of faults curve in a determined interval, say $T_{2}-T_{1}$, gives the cumulative probability of the faults.

\section{FTA FOR HEAVY FUEL OIL MARINE ENGINE SYSTEM}

Complex marine ship systems are subject to extensive range of faults. In order to determine the reliability of the system, several methods for practical overview of a system's operation in various events were developed. This has been done in order to achieve understanding of the formation of faults, how their probabilities can be assessed and how to reduce the likelihood of their occurrence analysing the safety and reliability of the system by identifying the weak points of the system.

To analyze and determine the reliability of the system, both qualitative and quantitative methods can/could be used and they refer to the methods of finding the probability of system survival for a period of time and for the prescribed working conditions (Blagojević, 2005).

There are two types of applicable procedures: inductive and deductive. The former is the result of subjective qualitative analysis. In deductive procedures, system analysis begins with potential faults and descends through the system in order to identify a potential component failure mode and human errors that can cause faults. Methods for these procedures are FTA (Fault Tree Analysis) and ETA (Event Tree Analysis) (Rao, 1992).

\subsection{Experiment case and results}

It has to be emphasized that the analysis of engine faults that have occurred in two years, using RCM (Reliability Centred Maintenance) can be found and are dominant in the heavyfuel-oil system (Bukša et al., 2008; Mokashi et al., 2002). Due to the reason mentioned, for this study a system of heavy-fuel-oil two stroke marine diesel engine MAN B\&W 5L90MC, has been chosen. A simulation has been conducted on the Full Mission Engine Room simulator Kongsberg Norcontrol. The main engine is low-speed 5-cylinder configuration, two-stroke, turbocharged, reversible diesel engine. The main engine specifications: cylinder bore $900 \mathrm{~mm}$; piston stroke 2,900 mm; number of cylinders 5; number of air coolers 2; number of turbo chargers 2; corresponding engine speed $74 \mathrm{rpm}$; mean indicated pressure 13.0 bar; scavenge air pressure 2.1 bar; turbine speed 8,000 rpm; specific fuel oil consumption $168 \mathrm{~g} / \mathrm{kWh}$.

Figure 4 shows fuel oil system of the mentioned marine diesel engine.

Heavy fuel oil preparation system consists of three phases:

1. phase: transfer of heavy fuel oil from storage tanks,

2. phase: purification of heavy fuel oil,

3. phase: supply of heavy fuel oil to the engine. 


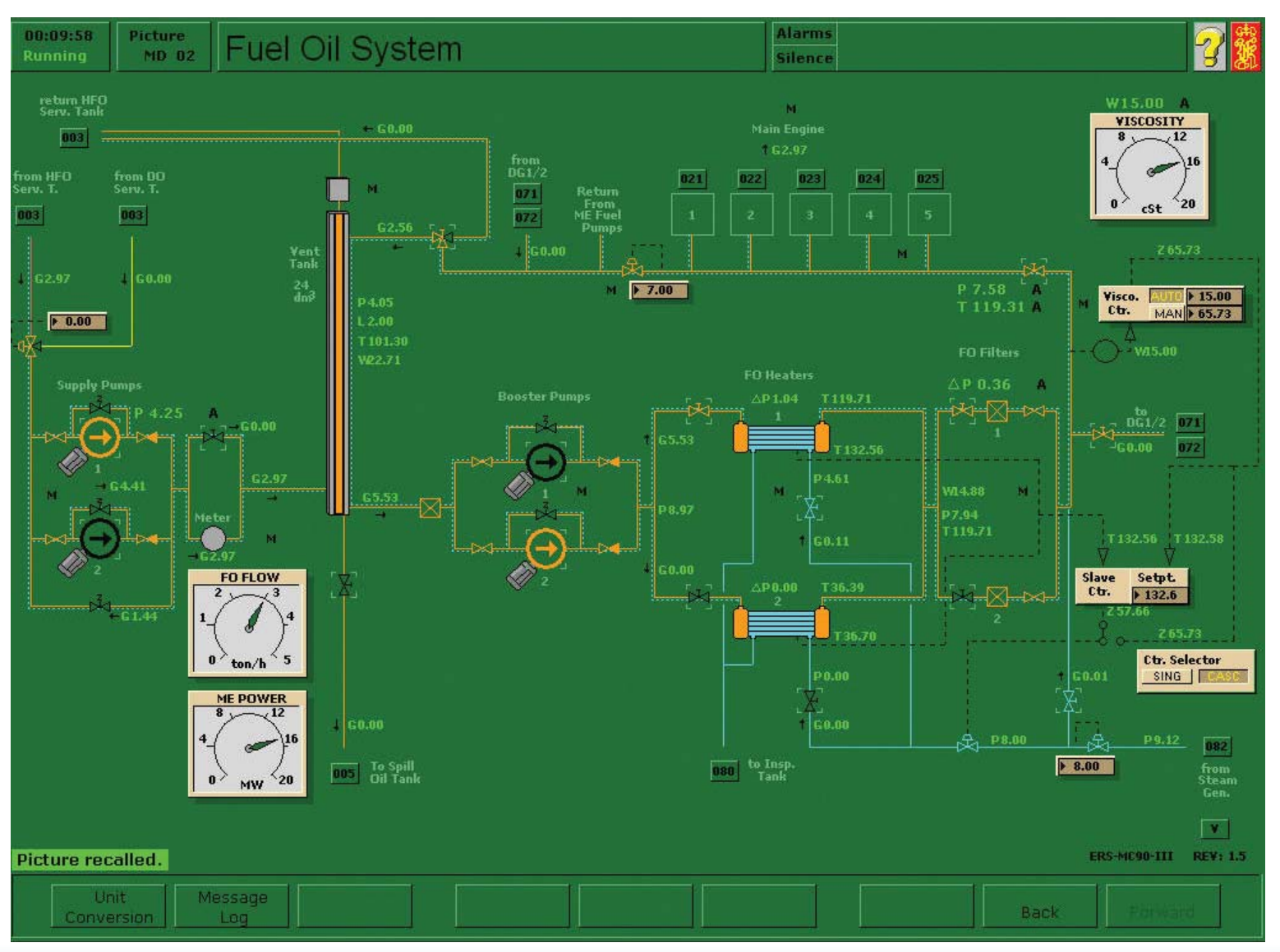

Figure 4.

Fuel oil system.

For the proposed study, the third phase in which lowpressure supply pumps take heavy fuel oil from the tanks and pressure it into a closed circulation loop, are of particular interest. Circulation (booster) pumps supply fuel oil from the injection pump to the engine through the heater, viscometer and filter. Excess fuel oil is returned from the engine and it is warmed to about $145^{\circ} \mathrm{C}$, then it is sent to the venting box and returned to the circulation loop, according to (Figure 4).

In this study special attention is paid to common faults that can happen to the heavy fuel oil supply pumps and have significant consequences for the engine fuel oil system.

In this paper, FTA deductive method structured in terms of events, in which the primary fault is determined, has been used. The FTA graphically illustrates the relationships between faults and symptoms. This method provides a more complete understanding of each functional relationship of the analyzed system and easier identification of the component causing the fault (Golub et al., 2011). It is especially used for identifying and analyzing the occurrence of critical damage, simplifying finding of individual component fault and thus giving the basic system reliability analysis. FTA, as opposed to the methods of inductive approach, using a graphical model allows displaying in a clear way of concatenation of different symptoms that can result in failure of these systems.

The interactive connection of events and symptoms that could lead to the given fault has been inferred by Boole's logic expression. A relevant top event is "Supply pump fault" and a possible fault tree for this event is presented in (Figure 4). The lowest level in the fault tree is the failure mode of a technical item. Some of these items are complex and it might be of interest to break them down into sub-items and attribute failures to latter. For example, the failure of the sound of cavitations (E6) may be split in two parts, individual failure (E7) or common cause failures (E8).

Such analysis indicates that for the successful functioning of the system essential correctness of all elements of the system matters. Also, it facilitates finding faults in the event of individual component failure, thus speeding up the fault localization and influences on the increase in system's reliability. 


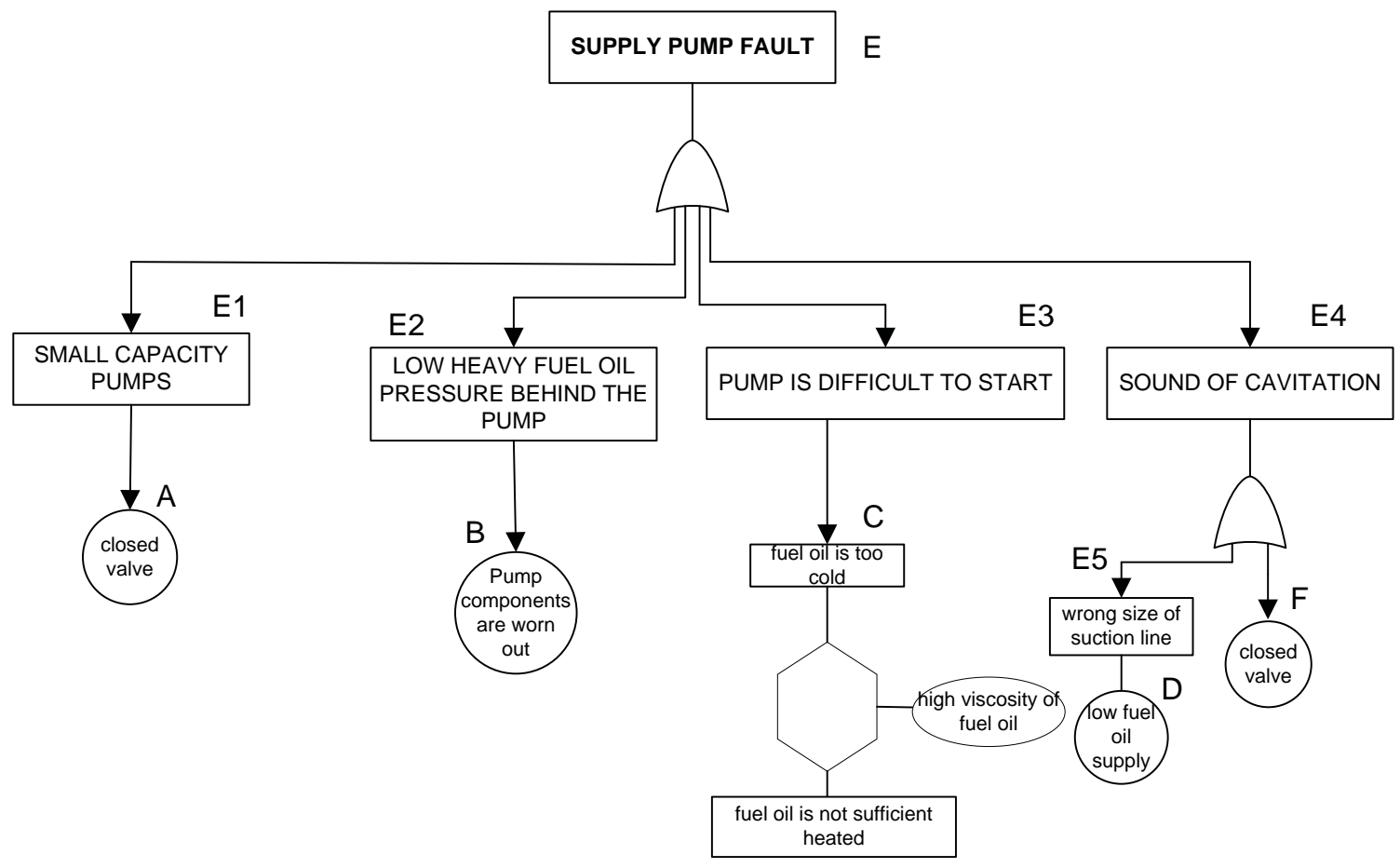

Figure 5.

Fault tree of heavy fuel oil supply pump.

$P(E)=P(E 1)+P(E 3)+P(E 4)+P(E 6)$

$P(E 1)=P(A)+P(E 2)-P(A) \cdot P(E 2)$

$P(E 2)=P(B)+P(C)-P(B) \cdot P(C)$

$P(E 3)=P(D)+P(E)-P(D) \cdot P(E)$

$P(E 4)=P(E 5)+P(G)-P(E 5) \cdot P(G)$

$P(E 5)=P(F)$

$P(E 6)=P(E 7)+P(E 8)+P(K)-P(E 7) \cdot P(E 8) \cdot P(K)$

$P(E 7)=P(H)$

$P(E 8)=P(I)+P(J)-P(I) \cdot P(J)$

The set theory is a general approach which allows us to organize the outcome events of an experiment to determine the appropriate probabilities (NASA, 2002). Using the set theory, fault tree concepts of heavy fuel oil separator can be expressed as (7):

With presented FTA analysis of heavy fuel oil supply pump, it is possible to conclude which precautions should be taken for correct operation of the supply pump or, to put it simply, which of the system parameters must be continuously monitored in order to achieve, through their optimization, a more reliable operation of the heavy fuel oil system.
Particular attention should be paid to the maintenance of fuel temperature since it affects the viscosity and density of the fuel and its fluctuations are undesirable. It is also desirable to monitor the pressure after the pump since resistance in the pressure pipe can occur, which has a significant impact on the correct operation of the pump.

\section{CONCLUSION}

Marine systems are complex technical systems. In order to achieve their reliability it is necessary to achieve reliability, functionality and quality interaction between their subsystems and components.

This paper studies the functional dependence of ship's systems on the appearance of faults. On board, except for the chance faults, the most common are wear-out faults. Considering that failures can occur of any system component and seriously undermine the reliability of the system as a whole, the goal of this study was to present one of the detailed methods of analyzing failures.

Due to very frequent failures in the engine fuel oil system, for research in this paper the system of heavy-fuel-oil two-stroke 
marine diesel engine MAN B \& W 5L90MC was chosen, and of particular interest were the possible failures on the heavy-fuel-oil supply pump.

This paper uses a deductive approach, or fault tree analysis method. This method is especially used in identifying and analyzing the occurrence of critical (disastrous) ways of damage, helps finding faults in case of individual component failure and thus provides the analysis of system reliability.

The system parameters that need to be continuously monitored in order not to jeopardize the reliability of the system were suggested to the featured FTA analysis.

Applying the proposed method showed suitable for a more complete understanding of each functional relationship between components in heavy-fuel-oil supply pump case. FTA maximally shortens the time required to find faults and failures which adds up to marine safety and protects the environment from pollution. Upon the occurrence of a fault it is simple, by observing the FTA diagram, to detect, localize and remove it in the shortest period of time. So, it can be concluded that FTA significantly contributes to reliability increase in the heavy-fuel-oil system and thus reflects on the reliability of other ship's systems.

\section{REFERENCES}

Barle, J., (2001), Općenito o eksploataciji, Skripta za studente, Split: Sveučilište u Splitu, FESB.

Blagojević, B., (2005), Modeliranje strukturnih sustava broda događajima, Ph.D. thesis, Zagreb: University of Zagreb, Faculty of Mechanical Engineering and Naval Architecture.

Bukša, A. and Šegulja, I., (2008), Pouzdanost brodskih sustava, Pomorstvo 22(2), pp. 259-270.

Golub, I., Antonić, R. and Dobrota, Đ., (2011), Optimizacija rada sustava brodskog separatora teškog goriva primjenom dijagnostičkih metoda zaključivanja, Scientific Journal of Maritime Research 25(1), pp. 173-188.

Lovrić, J., (1989), Osnove brodske terotehnologije, Dubrovnik: University of Split, Faculty of Maritime Studies in Dubrovnik.

Mokashi, A. J., Wang, J. and Vermar, A. K., (2002), A study of reliability-centred maintenance in maritime operation, Marine Policy, 26(5), pp. 325-335., http://dx.doi.org/10.1016/S0308-597X(02)00014-3

Mrčelić, G., (2010), Terotehnologija, Split: University of Split, Faculty of Maritime Studies in Split.

NASA, (2002), Fault tree handbook with aerospace application, Washington: Office of Safety and Mission Assurance, available at: http://www.hq.nasa.gov/office/ codeq/doctree/fthb.pdf, [accessed 12 June 2013.].

Rao, R. R., (1992), Reliability-based design, New York: McGraw-Hill. 